\title{
Granulation Tissue-induced Pseudo-relapse During Nivolumab Treatment in Advanced Non-small Cell Lung Cancer
}

\author{
CHIHIRO ANDO ${ }^{1}$, EIKI ICHIHARA ${ }^{1}$, HIROHISA KANO $^{2}$, YOSHITAKA IWAMOTO $^{2}$, ATSUKO HIRABAE $^{1}$, \\ TAKAMASA NAKASUKA ${ }^{2}$, YOSHINOBU MAEDA ${ }^{2}$ and KATSUYUKI KIURA ${ }^{1}$ \\ ${ }^{1}$ Department of Allergy and Respiratory Medicine, Okayama University Hospital, Okayama, Japan; \\ ${ }^{2}$ Department of Hematology, Oncology and Respiratory Medicine, Okayama University \\ Graduate School of Medicine, Dentistry and Pharmaceutical Sciences, Okayama, Japan
}

\begin{abstract}
Atypical tumor responses such as pseudoprogression or hyper-progression sometimes occur during immune check point inhibitor therapy. Distinct from both responses, we experienced a case of non-small cell lung cancer (NSCLC) with a pseudo-relapse, in which development of granulation mimicked cancer relapse during nivolumab therapy. A male with advanced NSCLC started nivolumab as a second-line therapy. After 15 cycles of nivolumab with a complete response, tumor markers started increasing and positron-emission computed tomography indicated a hot spot in the sigmoid colon. Laparoscopic segmental sigmoid colon resection revealed granulation tissue without any relapse of malignant cells. The results showed that even if radiographical tumor progression is found during immune therapy, histological confirmation should be considered.
\end{abstract}

Over the past several years, immune check point inhibitors (ICIs) such as anti-programmed cell death protein 1 (PD-1) and anti-programmed cell death ligand 1 (PD-L1) antibodies have dramatically changed systemic therapy for solid tumors, including non-small cell lung cancer (NSCLC). Nivolumab is an anti-PD-1 antibody that was approved as the first ICI for advanced NSCLC (1), followed by the development of pembrolizumab and atezolizumab. It is noteworthy that these ICIs can potentially cure advanced solid tumors. Traditionally,

This article is freely accessible online.

Correspondence to: Eiki Ichihara, MD, Ph.D., Department of Allergy and Respiratory Medicine, Okayama University Hospital, 2-5-1 Shikata-cho Kita-ku Okayama City, Okayama 700-8558, Japan. Tel: +81 862357227, Fax: +81 862328226, e-mail: ichihae@md.okayama-u.ac.jp

Key Words: Lung cancer, immune checkpoint inhibitors, nivolumab, granulation tissue. disease progression during systemic therapy has been determined with imaging, including computed tomography; now, however, with the use of ICIs, atypical tumor responses such as pseudo-progression (2) often occur, which makes it difficult to determine disease progression using only imaging. When considering potential cures and atypical responses, histological confirmation is becoming more important for determining disease progression.

We report a case of NSCLC with complete remission (CR) using nivolumab, which was accompanied by pseudo-relapse due to granulation tissue. In this case, diagnosis of pseudorelapse would not have been determined without histological examination.

\section{Case}

A 60-69-year-old male was diagnosed with unresectable pulmonary adenocarcinoma in April 2016 (Figure 1A). Initially, he received cisplatin and pemetrexed with a maximum partial response (PR), followed by subsequent disease progression. Nivolumab, started as second-line therapy in April 2017, significantly inhibited tumor growth, resulting in CR. After 15 cycles of nivolumab, serum carcinoembryonic antigen (CEA) levels started increasing and fluorodeoxyglucose (FDG) positron-emission computed tomography demonstrated marked FDG accumulation in localized abdominal lesions (Figure 1B, circled). Colonoscopy revealed a tumor in the sigmoid colon, and biopsy from the lesion showed only granulation tissue. Because the sigmoid lesion could be metastatic lung cancer and there was no other active lesion, he underwent sigmoidectomy for the purpose of diagnosis and radical therapy. Laparoscopic segmental sigmoid colon resection revealed a tumor penetrating from inside to the outside of the intestinal wall (Figure 2A). Histopathology revealed that the resected tumor developed beside a colon diverticulum and consisted of granulation tissue without any malignancy (Figure 2B). 

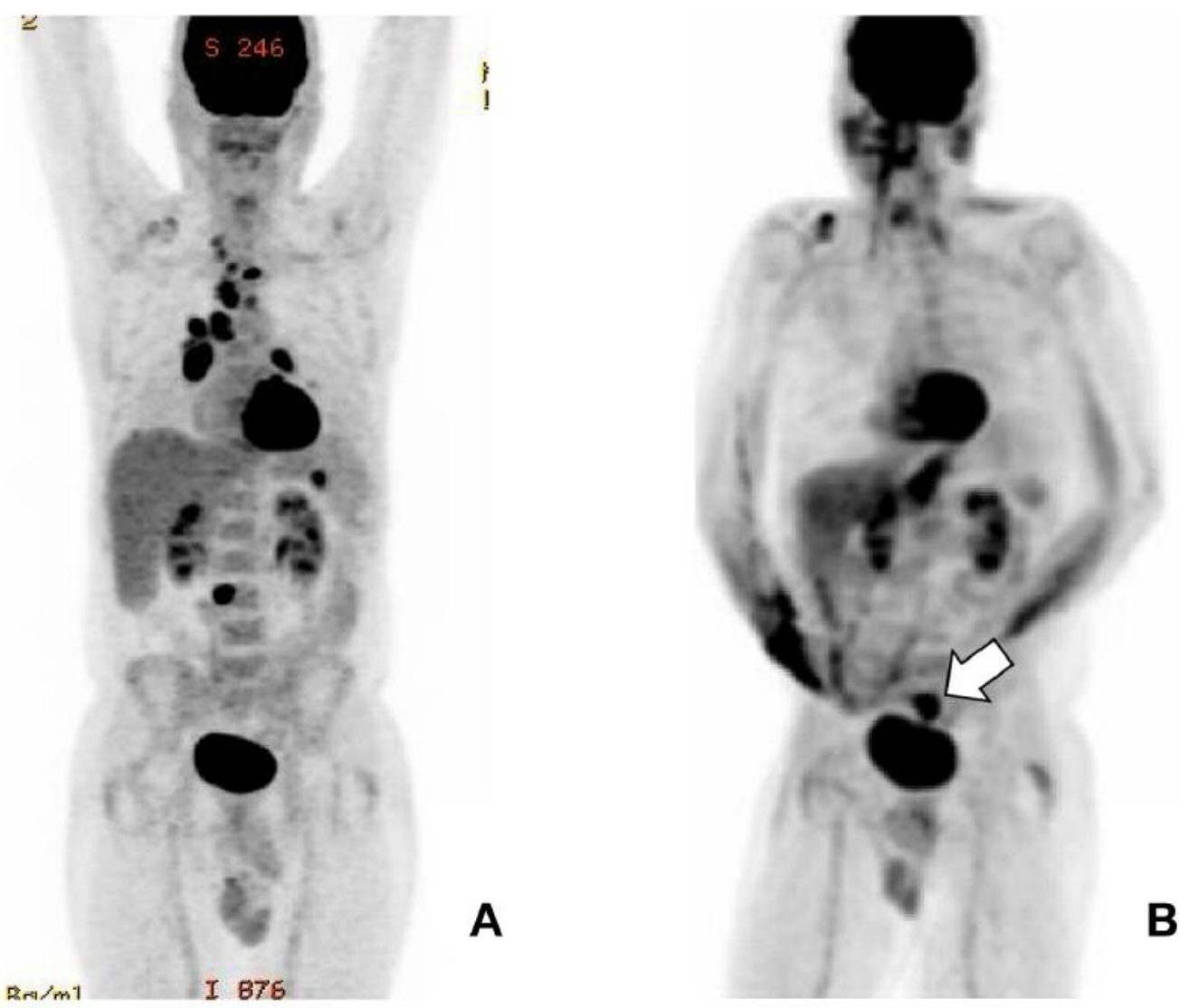

Figure 1. Fluorodeoxyglucose (FDG) positron-emission computed tomography (PET) image. A) Before nivolumab treatment, B) after nivolumab.


Figure 2. Macroscopic and microscopic images of the resected tumor. A) Macroscopic image of the resected tumor, B) Histology of the resected tumor. Food debris is recognized inside the granulation tissue. 
The patient had been treated with nivolumab for more than 1 year, without any recurrence, since the sigmoidectomy.

\section{Discussion}

We describe a case of NSCLC with a pseudo-relapse caused by granulation tissue during nivolumab treatment. To the best of our knowledge, there has been no other study reporting that granulation tissue mimics progression of NSCLC during ICI treatment.

Although a granuloma is totally different from granulation tissue, there are several reported cases that a granuloma, such as a sarcoid reaction, mimics tumor progression during treatment with ICIs (3-6). In many of these studies, a granuloma was histologically proven by enlarged lymph nodes, which spontaneously regressed. In our case, the colon lesion revealed no granuloma and did not regress for 6 months until surgery.

A diverticulum existed next to the granulation tissue, suggesting that a strongly activated immune reaction to diverticulitis might have occurred due to nivolumab, resulting in the formation of the granulation tissue. In addition, elevated CEA, which prompted us to suspect a tumor relapse, further increased transiently after the sigmoidectomy, followed by a subsequent decrease. Although the precise reason for elevated CEA remains unclear, it may have resulted from strong immunogenic inflammation. It is known that CEA increases due to benign inflammatory diseases such as pneumonia (7) as well as malignancy.

Because there is a chance of a potential cure with ICIs, even in advanced NSCLC (1) and, given that there are certain atypical responses to ICIs including pseudoprogression (2) and sarcoid reaction (8), we should asses tumor progression carefully and cautiously. Even if tumor progression is radiographically found, histological confirmation should be conducted.

\section{Conflicts of Interest}

There is no conflict of interest to declare regarding this study.

\section{Authors' Contributions}

Writing, review, and/or revision of the manuscript: Ichihara E; Writing and/or review: Ando C, Kano H, Iwamoto Y, Hirabae A, Nakasuka T, Maeda Y, Kiura K.

\section{References}

1 Borghaei H, Paz-Ares L, Horn L, Spigel DR, Steins M, Ready NE, Chow LQ, Vokes EE, Felip E, Holgado E, Barlesi F, Kohlhaufl M, Arrieta O, Burgio MA, Fayette J, Lena H, Poddubskaya E, Gerber DE, Gettinger SN, Rudin CM, Rizvi N, Crino L, Blumenschein GR Jr., Antonia SJ, Dorange C, Harbison CT, Graf Finckenstein F and Brahmer JR: Nivolumab versus docetaxel in advanced nonsquamous non-small-cell lung cancer. N Engl J Med 373(17): 1627-1639, 2015. PMID: 26412456. DOI: $10.1056 /$ NEJMoa1507643

2 Fujimoto D, Yoshioka H, Kataoka Y, Morimoto T, Hata T, Kim YH, Tomii K, Ishida T, Hirabayashi M, Hara S, Ishitoko M, Fukuda Y, Hwang MH, Sakai N, Fukui M, Nakaji H, Morita M, Mio T, Yasuda T, Sugita T and Hirai T: Pseudoprogression in previously treated patients with non-small cell lung cancer who received nivolumab monotherapy. J Thorac Oncol 14(3): 468474, 2019. PMID: 30468872. DOI: 10.1016/j.jtho.2018.10.167

3 Birnbaum MR, Ma MW, Fleisig S, Packer S, Amin BD, Jacobson $\mathrm{M}$ and McLellan BN: Nivolumab-related cutaneous sarcoidosis in a patient with lung adenocarcinoma. JAAD Case Rep 3(3): 208-211, 2017. PMID: 28443311. DOI: 10.1016/ j.jdcr.2017.02.015

4 Lainez S, Tissot C, Cottier M and Vergnon JM: Ebus-tbna can distinguish sarcoid-like side effect of nivolumab treatment from tumor progression in non-small cell lung cancer. Respiration 94(6): 518-521, 2017. PMID: 28910804. DOI: 10.1159/000480155

5 Noguchi S, Kawachi H, Yoshida H, Fukao A, Terashita S, Ikeue T, Horikawa $\mathrm{S}$ and Sugita T: Sarcoid-like granulomatosis induced by nivolumab treatment in a lung cancer patient. Case Rep Oncol 11(2): 562-566, 2018. PMID: 30186140. DOI: 10.1159/000492383

6 Paolini L, Poli C, Blanchard S, Urban T, Croue A, Rousselet $\mathrm{MC}$, Le Roux S, Labarriere $\mathrm{N}$, Jeannin $\mathrm{P}$ and Hureaux $\mathrm{J}$ : Thoracic and cutaneous sarcoid-like reaction associated with anti-pd-1 therapy: Longitudinal monitoring of pd-1 and pd-11 expression after stopping treatment. J Immunother Cancer 6(1): 52, 2018. PMID: 29898781. DOI: 10.1186/s40425-018-0372-4

7 Marechal F, Berthiot G and Deltour G: Serum levels of ca-50, ca-19.9, ca-125, ca-15.3, enolase and carcino-embryonic antigen in non neoplastic diseases of the lung. Anticancer Res 8(4): 677680, 1988. PMID: 3178158.

8 Gkiozos I, Kopitopoulou A, Kalkanis A, Vamvakaris IN, Judson MA and Syrigos KN: Sarcoidosis-like reactions induced by checkpoint inhibitors. J Thorac Oncol 13(8): 1076-1082, 2018. PMID: 29763666. DOI: 10.1016/j.jtho.2018.04.031

Received July 20, 2019

Revised August 13, 2019

Accepted September 14, 2019 